\title{
MECHANISM OF MASS TRANSFER OF INDICATOR IONS TO AN OXYGEN-EVOLVING AND A HYDROGEN- EVOLVING ELECTRODE IN ALKALINE SOLUTION
}

\author{
L. J. J. JANSSEN and E. BARENDRECHT
}

Laboratory for Electrochemistry, Department of Chemistry, Eindhoven University of Technology, P.O. Box 516, 5600 MB Eindhoven, The Netherlands

(Received $11 \mathrm{~J}$ uly 1984; in revised form 4 October 1984)

\begin{abstract}
A new convection-penetration model for mass transfer of indicator ions to a gas-evolving electrode at forced convection of solution is described theoretically. To check this model, the mass transfer coefficients for ferricyanide ions and ferrocyanide ions to, respectively, a hydrogern-evolving and an oxygenevolving electrode in $1 \mathrm{M} \mathrm{KOH}$ and at $298 \mathrm{~K}$ and various bulk-solution flow velocities have been determined in the usual way. The average diameter, cross-section and volume of detached bubbles and the efficiency of gas bubble evolution, have been determined photographically, however. It has been found that the mass transfer of indicator ions to a gas-evolving electrode can be described well by the new model. The contribution of an oxygen bubble departing from the electrode surlace to the mass transfer is much greater than the contribution of a departing hydrogen bubble.
\end{abstract}

\section{NOMENCLATURE}

$a_{d} \quad$ proportional factor

$A_{d} \quad$ average cross-section of detached bubbles; bubble cross-section $\left(\mathrm{m}^{2}\right)$

$A_{\text {s }} \quad$ surface area of electrode $\left(\mathrm{m}^{2}\right)$

$c_{i} \quad$ concentration of species $i$ in bulk of solution $\left(\mathrm{mol} \mathrm{m}^{-3}\right)$

d bubble density of sites from which bubbles depart $\left(\mathbf{m}^{-2}\right)$

$D_{i} \quad$ diffusion coefficient of species $i\left(\mathrm{~m}^{2} \mathrm{~s}^{-1}\right)$

$E$ electrode potential vs sce (V)

$F \quad=96.487 \times 10^{6} \mathrm{C} \mathrm{kmol}^{-1}$, Faraday constant

$h_{R S} \quad$ slope of $\log R_{S, d} / \log i$ curve

$i \quad$ electric current density $\left(\mathrm{kA} \mathrm{m}^{-2}\right)$

I electric current (kA)

$k_{i} \quad$ mass transfer coefficient of the indicator ion $i$ $\left(\mathrm{m} \mathrm{s}^{-1}\right)$

$k_{i}^{0} \quad$ mass transfer coefficient of the indicator ion $i$ in absence of forced convection or in a convectionless solution $\left(\mathrm{m} \mathrm{s}^{-1}\right)$

$k_{e, i}$ mass transfer coefficient of the indicator ion $i$ obtained by extrapolation of $k_{i} / i$ curve $\left(\mathrm{m} \mathrm{s}^{-1}\right)$

$k_{f, i} \quad$ mass transfer coefficient of the indicator ion $i$ at forced convection in absence of gas bubble evolution $\left(\mathrm{m} \mathrm{s}^{-1}\right)$

$k_{i} \quad$ mass cransfer coefficient of the indicalor ion $i$ in convectionless conditions for the part of electrode surface from which a bubble had departed $\left(\mathrm{m} \mathrm{s}^{-1}\right)$

$k_{i, a}^{\prime} \quad$ average value of $k_{i}^{\prime}$ for period $t_{d}\left(\mathrm{~ms} \mathrm{~s}^{-1}\right)$

$k_{f, i}^{\prime} \quad$ mass transfer coefficient of the indicator ion $i$ at forced convection for the part of electrode surface from which a bubble had departed $\left(\mathrm{ms}^{-1}\right)$

$k_{f, i . a}^{\prime}$ average value of $k_{f, i}^{\prime}$ for period $t_{1}\left(\mathrm{~m} \mathrm{~s}^{-1}\right)$

$k_{f, i, a *}^{\prime}$ average value of $k_{f, i}^{\prime}$ for period $t_{d}\left(\mathrm{~m} \mathrm{~s}^{-1}\right)$

$m_{i}$

mass fux density of the indicator ion $i\left(\mathrm{~mol} \mathrm{~m}^{-2} \mathrm{~s}^{-1}\right)$ number of detached bubbles per unit surface area and time $\left(\mathrm{cm}^{-2} \mathrm{~s}^{-1}\right)$

number of bubbles on a picture or on a part of a moving film (1)

number of electrons, involved in the reaction to form one molecule of a species (1)

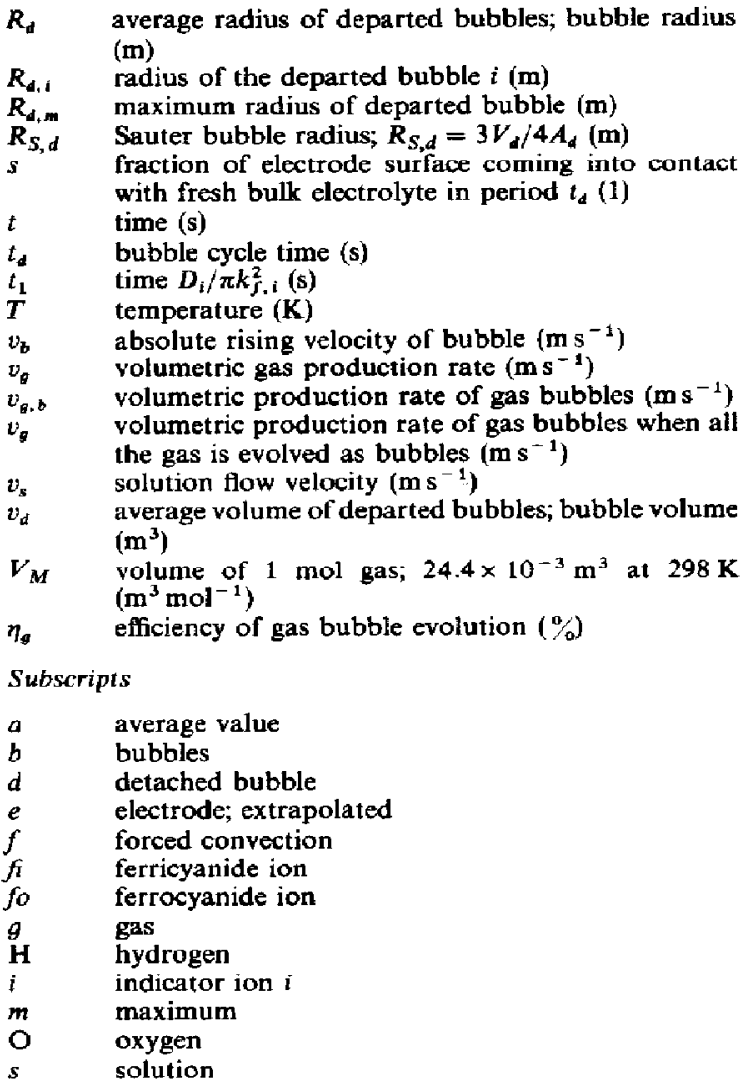

\section{INTRODUCTION}

Mass transfer at gas-evolving electrodes has been studied extensively over the last twenty years because 
of its great importance in various industrial processes, $e g$ chlorine, aluminium and zinc electrolysis. In particular, the mass transfer of indicator ions to a gasevolving electrode at natural convection has been thoroughly investigated and various mass transfer models are available [1-6].

Up till now, a model describing the mass transfer of indicator ions to a gas-evolving electrode at forced convection of bulk solution has not been presented in the literature. However, some empirical correlations [7, 8] to calculate the mass transfer coefficient $k$ for a gasevolving electrode at forced convection of bulk solution are given. The simplest correlation has been proposed by Beck[7], viz.

$$
k=k_{f}+k^{0}
$$

where $k_{f}$ is the mass transfer coefficient for hydrodynamic flow without the presence of bubbles; $k^{0}$ is the mass transfer coefficient for a gas-evolving electrode under natural convection conditions.

The main purpose of this study is to elucidate a model for the mass transfer of indicator jons to a gasevolving clectrode with superposition of hydrodynamic flow of solution. The proposed model is a modification of the coalescence model given by Janssen and van Stralen[4]. To check the modified model, it is necessary to determine some parameters characterizing detaching bubbles, and to determine the fraction of the gas formed which departs from the electrode surface in the form of bubbles. This fraction is called the efficiency of gas evolution[9].

So far, no experimental data on the efficiency of gas evolution are available and only some calculated results have been reported[9].

\section{EXPERIMENTAL}

\subsection{Determination of parameters of detached bubbles} and efficiency of gas evolution

2.1.1. Electrolytic cell and circuit. The electrolytic cell used in the optical experiments is sketched in Fig. 1. The working-electrode compartment and the two counter-electrode compartments are separated by porous glass diaphragms. The main part of the working-electrode compartment consists of a square

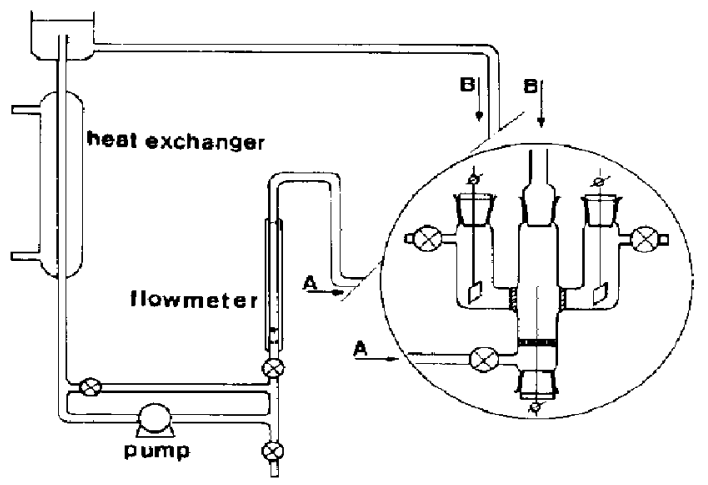

Fig. 1. Schematic diagram of electrolytic cell and solution circuit for optical experiments. tub with an inner cross-section of $10 \times 10 \mathrm{~mm}^{2}$ and a length of about $100 \mathrm{~mm}$.

The thermostatted solution was pumped through the working-electrode compartment; its volumetric flow rate was measured with a calibrated flowmeter (Fischer and Porter Tube: 3 F-3/8-25-5, Float CD-38, float material: glass density $2.28 \mathrm{~g} \mathrm{~cm}^{-3}$ ). This solution was saturated with oxygen or hydrogen, respectively, when oxygen or hydrogen experiments were carried out.

Special care was taken to prevent the presence of gas bubbles in the solution at the entrance of the workingelectrode compartment. The temperature of the solution in the working-electrode compartment was kept on $298 \mathrm{~K}$. To prevent solution-fiow instabilities and obtain a parallel solution flow, a grid was placed in the lowest part of the cell. Gas evolved at the counter electrodes left the cell via special valves.

The working electrode was a nickel wire $0.5 \mathrm{~mm}$ in diameter and $5.45 \mathrm{~mm}$ in length. This electrode was placed vertically in the middle of the tub opposite the glass diaphragms. Two platinum plates $30 \mathrm{~mm}^{2}$ each were used as the counter electrodes. The current has been adjusted galvanostatically. A $1 \mathrm{M} \mathrm{KOH}$ solution was used as electrolyte for all experiments.

After a pre-electrolysis of $1.5 \mathrm{~h}$ at the highest current in the series of experiments, experiments were carried out at decreasing current density. Four different solution-flow velocities, viz. $0.12,0.09,0.06$ and $0.04 \mathrm{~m} \mathrm{~s}^{-1}$ were used for oxygen evolution and only one, ie $0.12 \mathrm{~m} \mathrm{~s}^{-1}$ for hydrogen evolution.

2.1.2. Optical measurements. Against-the-light photography has been used to show the hydrogen and oxygen bubbles just above the working electrode. The experimental set-up used is practically the same as described in the literature $[10,16]$.

The bubbles were pictured by either photographs or moving films. The photographs were taken with a stil] camera. In this case a nanolite flashlight with a flash time of approximately 20 ns was used to take sharp pictures of the moving bubbles.

The film was taken with a high-speed film camera (Hitachi, type NAC 16D) with a picture frequency of 3000 frames per second to obtain sharply pictured bubbles.

Bubbles moving through a region, the lower edge of which is situated about $1 \mathrm{~mm}$ above the ton of the test electrode, were pictured in all optical experiments.

No bubbles rose outside the pictured region, which is $0.71 \mathrm{~mm}$ in width and $0.47 \mathrm{~mm}$ in height for the film. For the photograph the width is $1.46 \mathrm{~mm}$ and the height $0.97 \mathrm{~mm}$. Moreover, the depth of sharpness of the pictured region was sufficient to picture all the bubbles present in this region sharply. The photographs and the single films were analyzed as described in the literature $[10,16]$.

The high-speed films showed that the velocity of pictured bubbles was not equal to that of the flow of the bulk solution. Consequently, the single photograph experiments are not uscful in determining the efficiency of gas evolution.

To obtain the volumetric rate of gas-bubble evolution, the diameter of each bubble moving across a fixed straight on the film pictures, taken during a fixed time, was measured. 
The measured bubbles in these pictures, about 100 to 200 , were also used to determine the bubble parameters. These parameters were also obtained from the bubbles shown on five photographs. In this case the diameter of about 30 bubbles was measured.

\subsection{Determination of rate of mass transfer at forced convection}

2.2.1. Electrolytic cell and electrolyte circuits. The electrolytic cell used for all mass transfer experiments is a two-compartment acrylate cell, the compartments being separated by an ion-exchange membrane (Nation, type 427). Parts of the electrolytic cell are schematically shown in Fig. 2. The inner dimensions of both compartments are the same: height $100 \mathrm{~mm}$, width $30 \mathrm{~mm}$ and depth, the distance from the membrane to the inner back-wall of the rectangular compartment, $10 \mathrm{~mm}$. In each compartment the solution inlet and outlet are at the bottom and top, respectively. An acrylate support of the working electrode was placed in the working-electrode compartment, so that the cross-section of solution flow at the level of the working electrode was $100 \mathrm{~mm}^{2}$ and the distance from the working electrode to the membrane $7.5 \mathrm{~mm}$. The working electrode was $8.0 \mathrm{~mm}$ in width and $60 \mathrm{~mm}$ in height; it was insulated at the rear. The counter electrode, made of Veco gauze, had the same geometrical dimensions and was pressed against the membrane just opposite the working electrode.

Solution circuits similar to the one schematically represented in Fig. 1 were used for both compartments of the cell. The size of the solution reservoir was

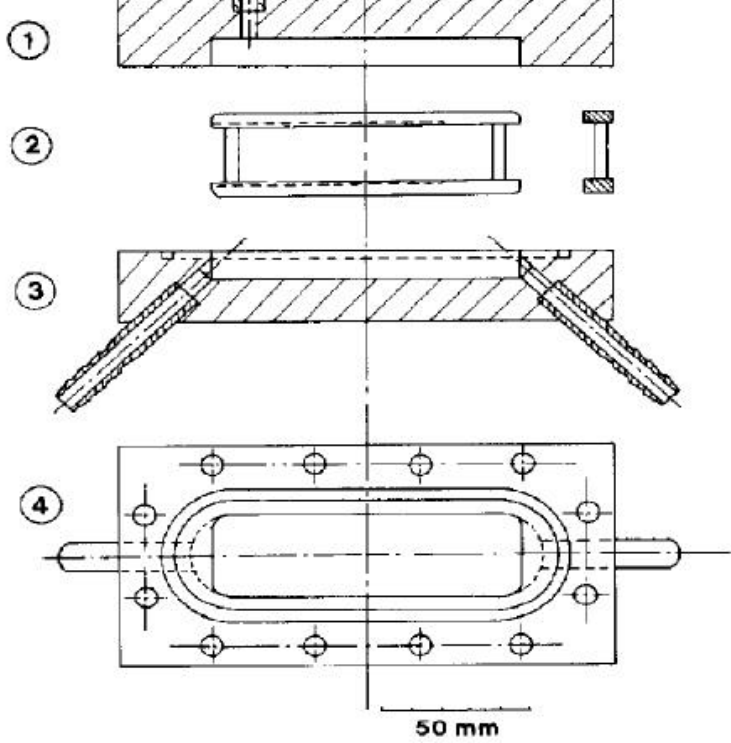

Fig. 2. Schematic diagramof electrolytic cell for mass transfer experiments. 1, Cross-section A-B of working electrode compartment. 2, Top view of electrode support. 3, Crosssection A-B of counter electrode compartment. 4, Top view of counter electrode compartment. sufficient to allow all bubbles to escape from the circulating solution. For bulk-solution-flow velocities higher than $0.12 \mathrm{~m} \mathrm{~s}^{-1}$ the CD-38 float was replaced by a SS-38 float of stainless steel with a density of $8.02 \mathrm{~g} \mathrm{~cm}^{-3}$.

2.2.2. Electrolyte, analysis and procedure. A $1 \mathrm{M} \mathrm{KOH}$ solution was used as supporting electrolyte for all experiments. To determine the mass transfer coefficients for the oxygen-evolving electrode and the hydrogen-evolving electrode, respectively, $\mathrm{K}_{4} \mathrm{Fe}(\mathrm{CN})_{6}$ and $\mathrm{K}_{3} \mathrm{Fe}(\mathrm{CN})_{6}$, were added to the supporting electrolyte[11]. At the beginning of a series of experiments the concentration of the indicator ion was about $0.05 \mathrm{M}$, unless otherwise stated. The quantity of $\mathrm{Fe}(\mathrm{CN})_{6}^{3-}$ formed during the oxygen evolution was determined iodometrically and the quantity of $\mathrm{Fe}(\mathrm{CN})_{6}^{4-}$ formed during the hydrogen evolution was obtained by titration with $\mathrm{Ce}^{4+}[12]$.

The rate of mass transfer was determined for series of experiments in sequence of decreasing current density at constant solution-flow velocity or increasing solution-flow velocity at constant current density.

The following procedure was usually applied. Before each series of experiments the working electrode was polarized in the supporting electrolyte for $60 \mathrm{~min}$ at the highest current density of the projected series of experiments, unless otherwise stated. After this pre-electrolysis and, without current switch-off, a calculated quantity of solution containing $1 \mathrm{M} \mathrm{KOH}$ and $1 \mathrm{M} \mathrm{K}_{3} \mathrm{Fe}(\mathrm{CN})_{6}$ or $1 \mathrm{M} \mathrm{K}_{4} \mathrm{Fe}(\mathrm{CN})_{6}$ was added to the working-electrode compartment to obtain a $\mathrm{K}_{3} \mathrm{Fe}(\mathrm{CN})_{6}$ concentration of $0.05 \mathrm{M}$.

As soon as the solution was homogeneous, a $25 \mathrm{~cm}^{3}$ sample of solution was taken and analysed. After a polarization time of $20 \mathrm{~min}$ the next projected current in the series of experiments was adjusted and a $25 \mathrm{~cm}^{3}$ sample was taken again. The same procedure was applied for the subsequent currents in the series of experiments. No current interruption occurred during the whole series of experiments. The series of experiments with various solution-flow velocities were carried out analogously.

The maximum decrease in $\mathrm{K}_{4} \mathrm{Fe}(\mathrm{CN})_{6}$ or $\mathrm{K}_{3} \mathrm{Fe}(\mathrm{CN})_{6}$ concentration for an experiment in a series was about $6 \%$. Moreover, during a series of experiments, the volume of the solution in the workingelectrode compartment became smaller because of sample taking. Both effects were corrected for.

\section{RESULTS}

3.1. Parameters characterizing the behaviour of detached bubbles

In order to characterize the bubble behaviour, the following parameters have been determined from pictures with $n$ bubbles of a certain region just above the top of the working electrode:

$\boldsymbol{R}_{d, i}$ : radius of bubble $i$

$R_{d} \quad$ : bubble radius; $R_{d}=\sum_{i=1}^{n} R_{d, d} / n$

$A_{d} \quad$ : bubble cross-section; $A_{d}=\sum_{i=1}^{n} \pi R_{d, i}^{2} / n$ 
$V_{d} \quad$ : bubble volume; $\quad V_{d}=\sum_{i=1}^{n} 4 / 3 \pi R_{d, i}^{3} / n$

$R_{\mathrm{d}, m}$ : maximum of $R_{d, i}$

$R_{S, d}$ : Sauter bubble radius; $R_{S, d}=3 V_{d} / 4 A_{d}$

3.1.1. Oxygen bubbles. The Sauter bubble radius is shown as a function of current density $i_{0}$ at various bulk-solution-flow velocities in Fig. 3 for the photographic method and in Fig. 4 for the high-speed moving film method. Both optical methods give practically the same results. The slight differences in $R_{S, d}$ are not caused by the difference in experimental technique but by a difference in nature of the electrode surface for the series of experiments. It is well known that, in particular, nucleation properties of an electrode surface are very sensitive to pre-treatment or history of that surface.

In Fig. 3 only two curves have been drawn; one for the results at $v_{s}=0.12 \mathrm{~m} \mathrm{~s}^{-1}$ and the other for those at the other three solution flow velocities. Because of the small number of experimental results and the slight differences for the four solution-flow velocitjes, only one curve has been drawn in Fig. 4. Figures 3 and 4 show that $\log R_{S, d}$ increases linearly with increasing $\log i_{\mathrm{O}}$ up to about $i_{\mathrm{O}}=2 \mathrm{kA} \mathrm{m}^{-2}$ and more slowly at higher current densities $i_{0}$. The slope $h_{R_{1} s}$ of the $\log R_{S, d} / \log i_{O}$ curve is 0.41 at $v_{s}=0.12 \mathrm{~m} \mathrm{~s}^{-1}$ and 0.37 at lower solution-flow velocities.

It has been found that the $\log R_{d} / \log i_{\mathrm{O}}$, $\log R_{d, m} / \log i_{O}, \log A_{d} / \log i_{\mathrm{O}}$ and $\log V_{d} / \log i_{\mathrm{O}}$ curves are linear. Their respective slopes $h_{R}, h_{R, m}, h_{d}$ and $h_{v}$ are independent of the bulk solution flow velocity $v_{s}$. For the photographic method the following relations for $R_{d}, R_{d, m}, A_{d}$ and $V_{d}$ at $v_{s}=0.12 \mathrm{~m} \mathrm{~s}^{-1}$ have been obtained:

$$
\begin{gathered}
R_{\mathrm{d}}=2.6 \times 10^{-5} i_{\mathrm{O}}^{0.44} \mathrm{~m}, \quad R_{d, m}=22 \times 10^{-5} i_{\mathrm{O}}^{0.28} \mathrm{~m}, \\
A_{d}=2.4 \times 10^{-9} i_{\mathrm{O}}^{0.85} \mathrm{~m}^{2} \\
\text { and } V_{d}=1.2 \times 10^{-13} i_{\mathrm{o}}^{1.21} \mathrm{~m}^{3}
\end{gathered}
$$

where $t$ is given in $\mathrm{kA} \mathrm{m}^{-2}$. The estimate inaccuracy of the exponents of $i$ is about $5 \%$

High-speed films showed that at $v_{s}=0.12 \mathrm{~m} \mathrm{~s}^{-1}$ the bubble velocity $v_{b}$ increases from 0.045 to $0.075 \mathrm{~m} \mathrm{~s}^{-1}$ at an increase in current density from 0.1 to $10 \mathrm{kA} \mathrm{m}^{-2}$. At $v_{s}=0.04 \mathrm{~m} \mathrm{~s}^{-1}$ the bubble velocity $v_{b}$ was higher than $v_{s}$ at $i_{O}$ from 1 to $10 \mathrm{kA} \mathrm{m}^{-2}$ and lower at $i_{O}$ $=0.1 \mathrm{kA} \mathrm{m}^{-2}$. Moreover, it has been found that at a constant current density and bulk solution flow, the bubble velocity is almost independent of bubble size, despite a large difference in bubble size. The diameter of the detached bubbles lies between 50 and $120 \mu \mathrm{m}$ at $i_{\mathrm{O}}=10 \mathrm{kA} \mathrm{m}^{-2}$ and $v_{\mathrm{s}}=0.12 \mathrm{~m} \mathrm{~s}^{-1}$.

3.1.2. Hydrogen bubbles. Pictures of detached hydrogen bubbles were made for only one optical technique, viz the high-speed film method and for only one bulk-solution-flow velocity, viz $0.12 \mathrm{~m} \mathrm{~s}^{-1}$.

The Sauter bubble radius is plotted as a function of current density $i_{\mathrm{H}}$, on double logarithmic scale in Fig. 5 . This figure shows that $\boldsymbol{R}_{S, d}$ increases at a decreasing rate with increasing current density. In the current density range from 0.1 to $1 \mathrm{kA} \mathrm{m}^{2}$, the experimental results can also be described by a straight line with a slope $h_{R, S}$ of about 0.25 . It has also been found that $\log R_{d}, \log R_{d, m}, \log A_{d}$ and $\log V_{d}$ increase linearly with increasing $\log i_{\mathrm{H}}$. The slopes $h_{R}, h_{R, m}, h_{A}$ and $h_{V}$ are, respectively, $0.27,0.25,0.61$ and 0.97 . The estimate inaccuracy of these slopes is about $5 \%$. The parameters $R_{d}, R_{d, m}, A_{d}$ and $V_{d}$ are given by the following relations: $\quad R_{d}=2.9 \times 10^{-5} i_{H^{0.27}}^{0}, \quad R_{d . m}=7.5$ $\times 10^{-5} i_{\mathrm{H}}^{0.25} \mathrm{~m}, A_{d}=4.5 \times 10^{-9} i_{\mathrm{H}}^{0.61} \mathrm{~m}^{2}$ and $V_{\mathrm{d}}=3.0$ $\times 10^{-13} i_{\mathrm{H}}^{0.97} \mathrm{~m}^{3}$ were $i_{\mathrm{H}}$ is given in $\mathrm{kA} \mathrm{m}^{-2}$.

\subsection{Efficiency of gas evolution}

The volumetric rate $v_{g, b}$ of gas evolution has been determined from high-speed films. The efficiency of gas evolution $\eta_{g}=100 v_{g, b} / v_{g}^{\circ}$ is calculated. From this rate and the theoretical one, viz $v_{g}^{0}=n F i_{g} V_{M}$ where $V_{M}$ is

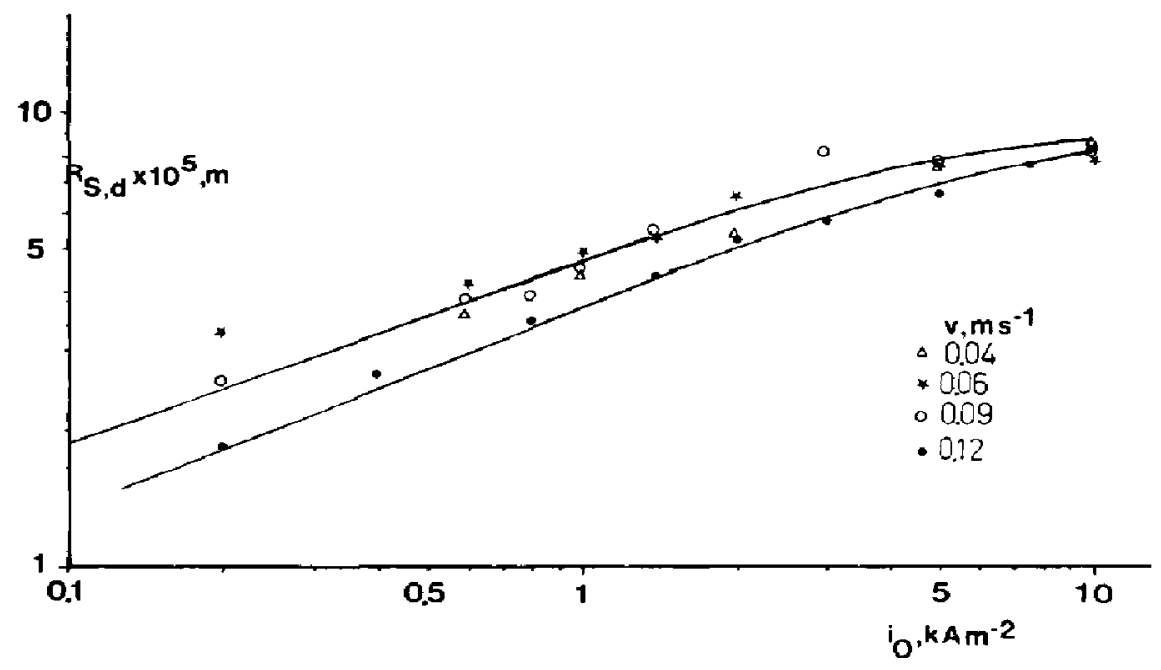

Fig. 3. Sauter bubble radius, determined by the photographic method, as a function of current density for oxygen evolution on a nickel electrode in $1 \mathrm{M} \mathrm{KOH}$ and at $298 \mathrm{~K}$ and vartous bulk-solution-flow velocites vs. 


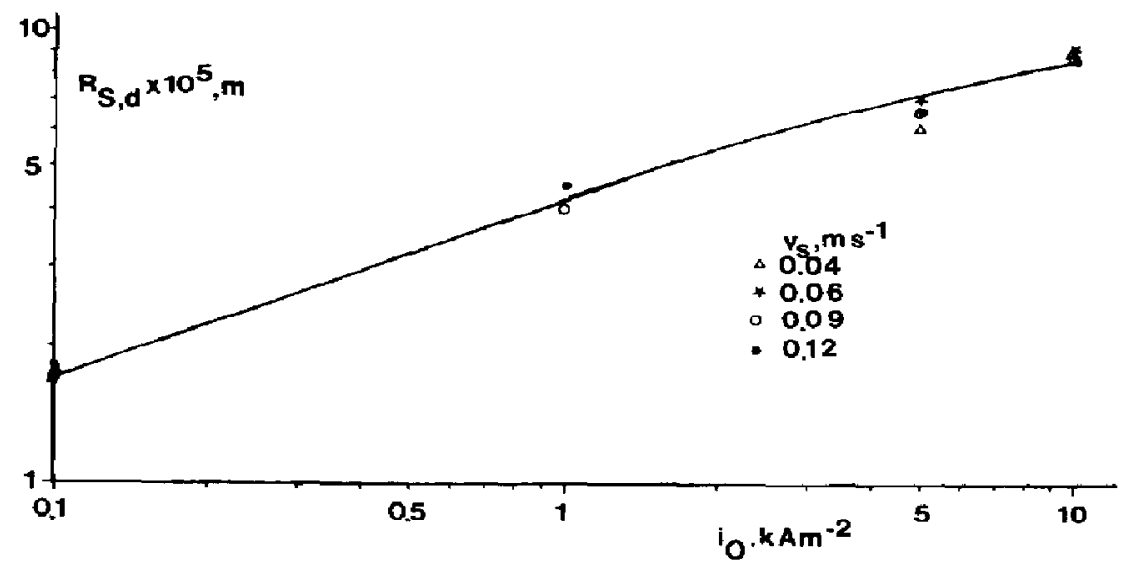

Fig. 4. Sauter bubble radius, determined by the high speed film method, as a function of current density for oxygen evolution on a nickel electrode in $1 \mathrm{M} \mathrm{KOH}$ and at $298 \mathrm{~K}$ and various bulk-solution-flow velocities $v_{s}$

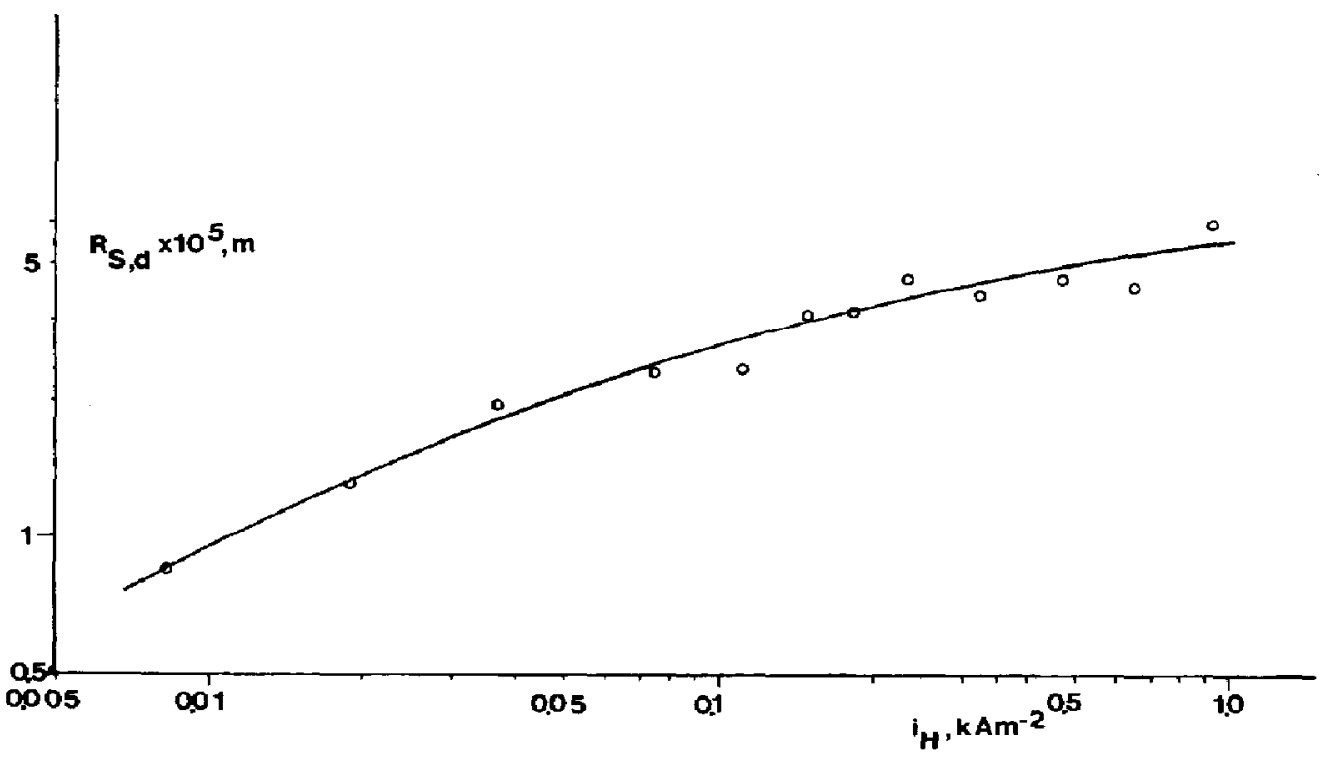

Fig. 5. Sauter bubble radius, determined by the high speed film method, as a function of current density for hydrogen evolution on a nickel electrode in $1 \mathrm{M} \mathrm{KOH}$ and at $298 \mathrm{~K}$ and at a bulk-solution-fow velocity of $0.12 \mathrm{~ms}^{-1}$

the volume of $1 \mathrm{~mol}$ gas $\left(Y_{M}=24.4 \times 10^{-3} \mathrm{~m}^{3} \mathrm{~mol}^{-1}\right.$ at $298 \mathrm{~K}$ ).

In Fig. $6 \eta_{e}$ has been given as a function of current density $i_{0}$ at various velocitics of bulk-solution flow. The results of Fig, 6 are remarkable; only about half of the oxygen formed is evolved in the form of bubbles and the other part is transported in the dissolved state from the electrode surface.

Figure 7 shows the efficiency of gas evolution as a function of current density $i_{\mathrm{H}}$ at $v_{s}=0.12 \mathrm{~m} \mathrm{~s}^{-1}$. Taking experimental inaccuracy into account, it is likely that $\eta_{g}$ is practically constant, ie $75 \%$, in the current density range from 0.05 to $1.0 \mathrm{kA} \mathrm{m}^{-2}$. Figures 6 and 7 show that $\eta_{g}$ for hydrogen is clearly higher than $\eta_{g}$ for oxygen.

\subsection{Mass transfer coefficient}

The redox couple $\mathrm{Fe}(\mathrm{CN})_{6}^{3-} / \mathrm{Fe}(\mathrm{CN})_{6}^{4-}$ is very useful in determining the mass transfer coefficient $k_{i}$ for the hydrogen-evolving electrode at $i_{\mathrm{H}}>$ $\simeq 0 \mathrm{~mA} \mathrm{~cm}^{-2}$ as weil as for the oxygen-evolving electrode at $i_{0}>\simeq 10 \mathrm{~mA} \mathrm{~cm}^{-2}[13]$, since under these conditions the concentration of the indicator ion at the surface of the gas-evolving electrode is practically zero.

In this case, the mass transfer coefficient $k_{i}$ of indicator ion $i$ to a gas-evolving electrode is calculated with the well known equation

$$
k_{i}=m_{i} / A_{e} c_{i}
$$

where $m_{i}$ is the rate of oxidation or reduction of 


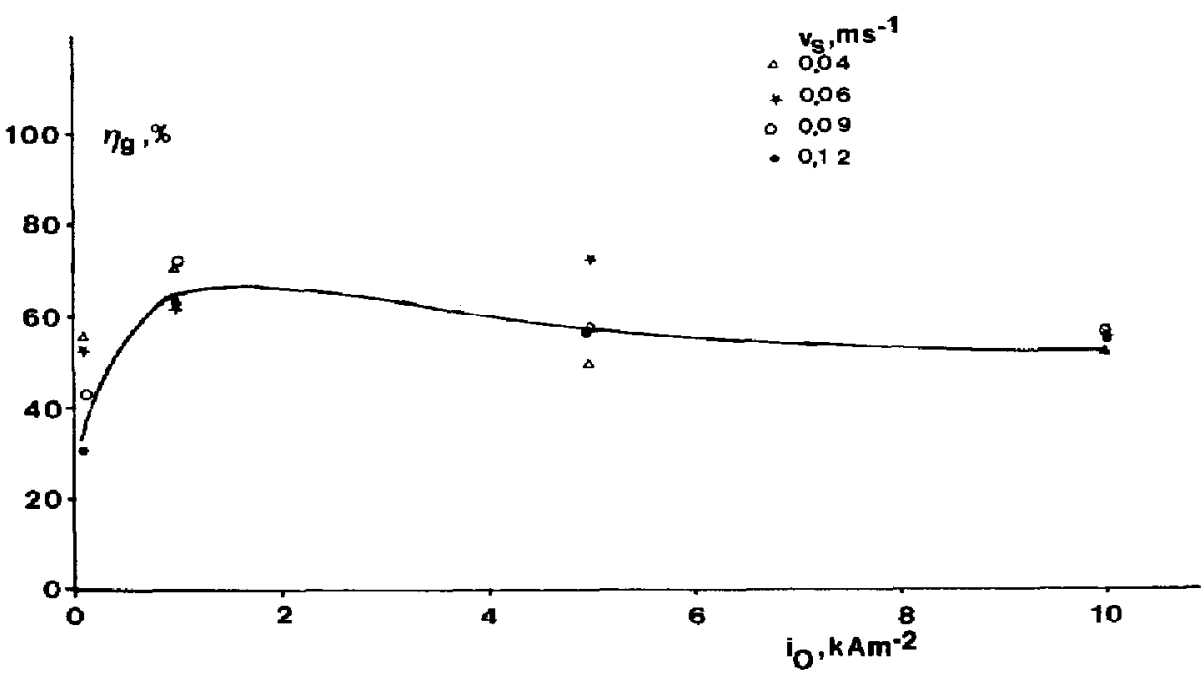

Fig. 6 . Efriciency or yas bubble evulut iun as a function of $i_{O}$ for oxygen evolution on a nickel clect rode in $1 \mathrm{M}$ $\mathrm{KOH}$ and at $298 \mathrm{~K}$ and various bulk-solution-flow velocities $v_{s}$.

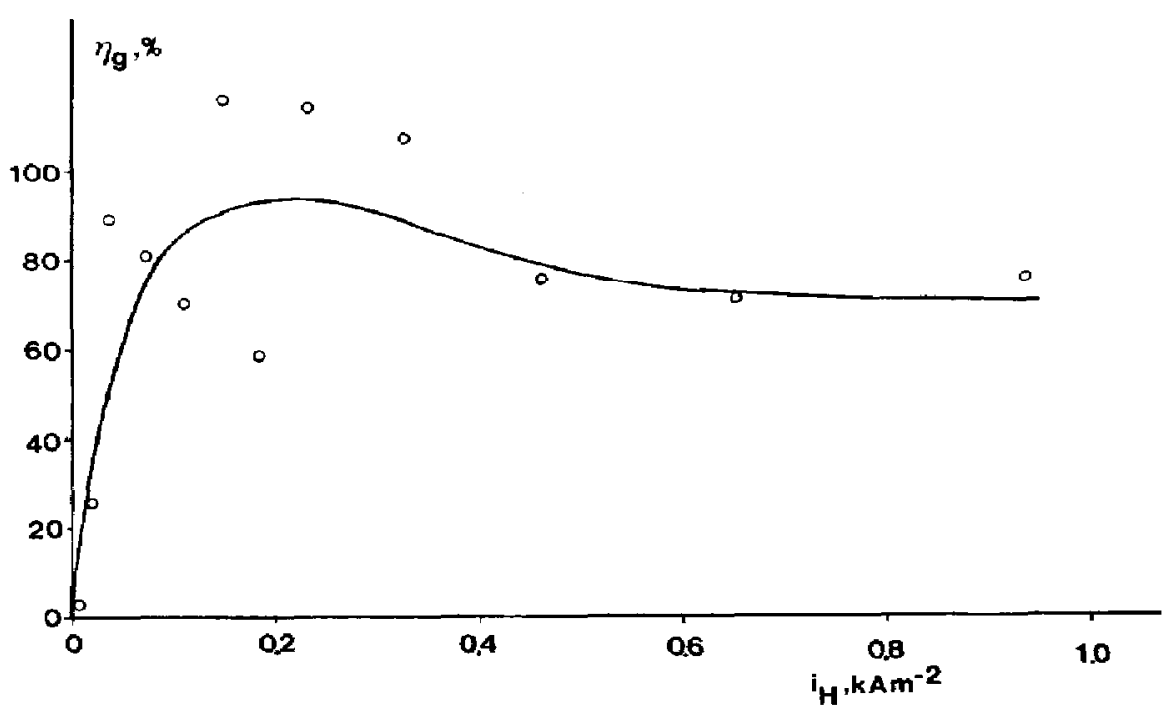

Fig. 7. Efficiency of gas bubble evolution as a function of current density for hydrogen evolution on a nickel electrode in $1 \mathrm{M} \mathrm{KOH}$ and at $298 \mathrm{~K}$ and a bulk-solution-flow velocity of $0.12 \mathrm{~m} \mathrm{~s}^{-1}$.

indicator ions, $A_{*}$ is the electrode surface area and $c_{i}$ is the concentration of the indicator ion in the bulk of the solution.

In the calculation of $k_{i}$, the average concentration of the indicator ion during the experiment was used.

The current for formation of oxygen or hydrogen $i_{0}$ or $i_{H}=i-i_{i}$ where $i$ is the adjusted current density and $i_{i}$ is the current density for the oxidation or reduction of indicator ions. The current density $i_{i}=n F m_{i}$.

3.3.1. Oxygen-evolving electrode. To determine the dependence of $k_{f o}$ on $i_{\mathrm{O}}$, mass transfer experiments were also carried out up to about $10 \mathrm{kA} \mathrm{m}^{-2}$. It has been found that $k_{f_{0}}=k_{c_{\text {, sa }}}+P_{Q} i^{0.85}$ for $v_{s}$ from 0.04 to $0.12 \mathrm{~m} \mathrm{~s}^{-1}$ and $k_{e, s a}$ is higher than $k_{f, f o}$, where $k_{\text {f, so }}$ is the mass transfer coefficient for $\mathrm{Fe}(\mathrm{CN})_{6}^{4}-$ at forced convection and without gas evolution. Moreover, $p_{0}$ decreases with increasing $v_{s}$. The mass transfer coefficient $k_{\text {so }}$ is given in Fig. 8 as a function of $i_{0}^{85}$ for an oxygen-evolving nickel electrode in $1 \mathrm{M} \mathrm{KOH}$ as supporting electrolyte, at $298 \mathrm{~K}$ and various $v_{s}$. The results at $i_{\mathrm{O}}=0 \mathrm{kA} \mathrm{m}^{-2}$ were obtained from experiments by measuring the current of $\mathrm{Fe}(\mathrm{CN})_{6}^{3-}$ reduction at a potential of $450 \mathrm{mV}$ vs sce. At this potential the limiting current for oxidation of Fe(CN) $)^{4-}$ was obtained.

Linear extrapolation of a $k_{f o} / i_{0}^{8.85}$ curve gives $k_{f o}$ at 


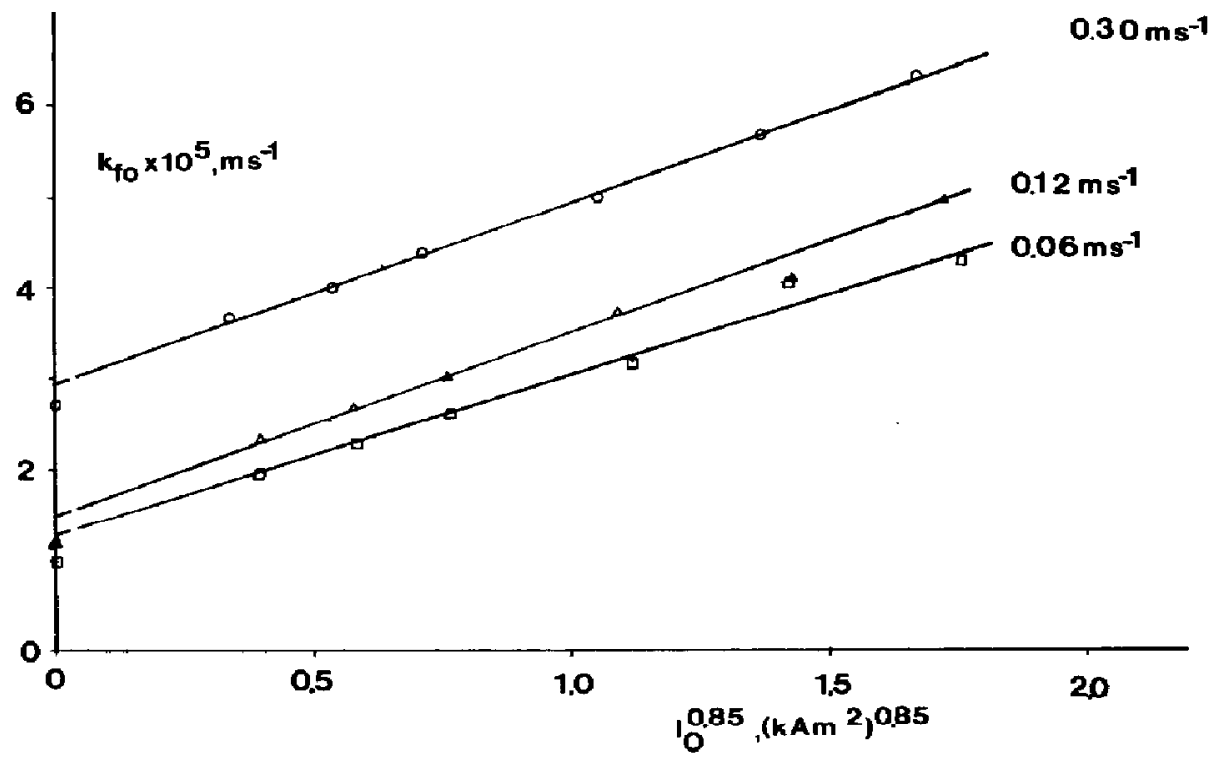

Fig. 8. Mass transfer coefficient for $\mathrm{Fe}(\mathrm{CN})_{6}^{4-}$ to an oxygen-evolving nickel electrode in $1 \mathrm{M} \mathrm{KOH}$ and at $298 \mathrm{~K}$ and three different bulk-solution velocities is plotted us the curfent density of oxygen cvolution.

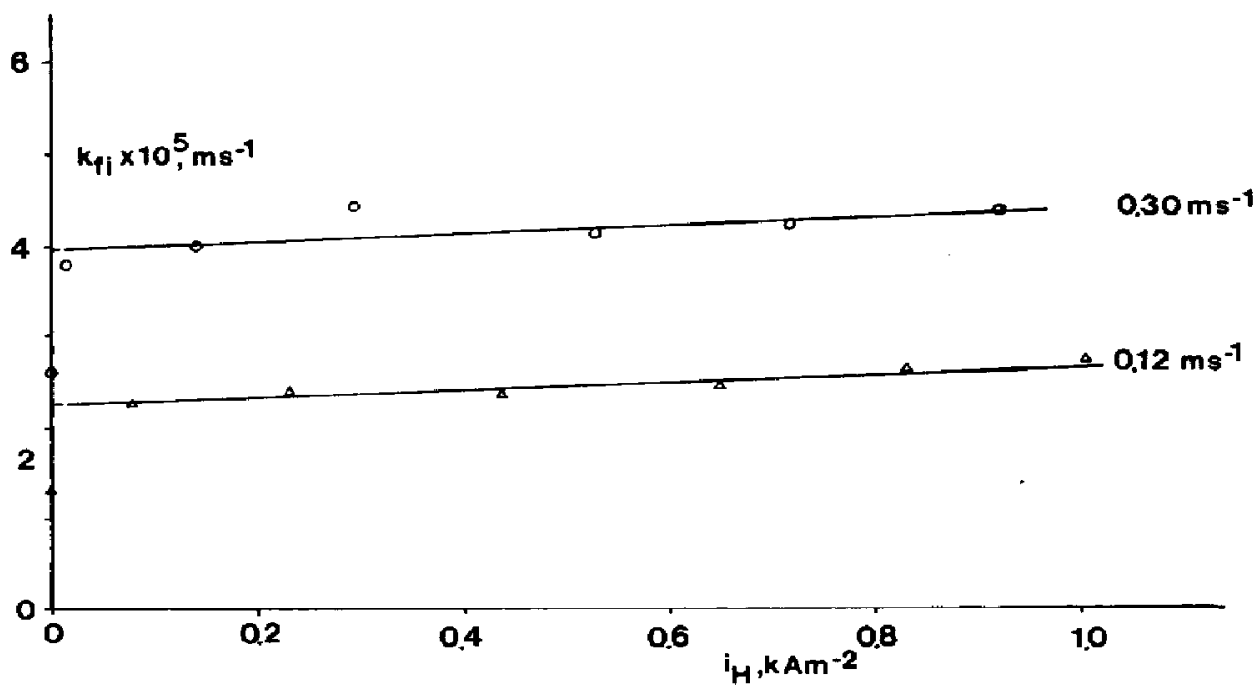

Fig. 9. Mass transfer coefficient for $\mathrm{Fe}(\mathrm{CN})_{6}^{3-}$ to a hydrogen-evolving nickel electrode in $1 \mathrm{M} \mathrm{KOH}$ and at $298 \mathrm{~K}$ and two different bulk-solution flow velocities $v_{s}$ is plotted $v s$ the current density of hydrogen evolution.

$i_{\mathrm{o}}=0 \mathrm{kAm}{ }^{2}$, denoted by $k_{e, f o}$. Figure 8 shows that $k_{e, f o}$ is larger than $k_{f, f_{a}}$.

3.3.2. Hydrogen-evolving electrode. Figure 9 shows the mass transfer coefficient $k_{f_{i}}$ as a function of $i_{\mathrm{H}}$ for a hydrogen-evolving electrode in $1 \mathrm{M} \mathrm{KOH}$ as supporting electrolyte, at $298 \mathrm{~K}$ and two different flow velocities. The mass transfer coefficient $k_{f, f i}$ was determined by measuring the current at a working electrode potential of -0.5 V. From Fig. 9 it follows that the slight increase in $k_{f i}$ is proportional to $i_{\mathrm{H}}$. Linear extrapolation of the straight lines of Fig. 9 gives $k_{e, f_{i}}$. Figure 9 shows that both velocities of solution flow $k_{\text {e. } f i}$ are clearly higher than $k_{f, f i}$. To check the relation between $k_{f i}$ and $i_{\mathrm{H}}$, represented in Fig. 9, mass transfer experiments were also carried out at up to $i_{H}$ is about $10 \mathrm{kA} \mathrm{m}^{-2}$. It has been found that $k_{f i}=k_{e, r i}$ $+p_{\mathrm{H}} i_{\mathrm{H}}$ and $p_{\mathrm{H}}$ decreases with increasing $i_{\mathrm{H}}$. 


\section{THEORY}

The rate of mass transfer of indicator ions to a gasevolving electrode is described by a new model. In this model only the detaching bubbles are taken into consideration. This means that the adhered bubbles have no influence upon the rate of mass transfer.

The formation, growth and detachment of a bubble on a site of the electrode surface require a time $t_{d}$. On the same site this phenomenon is constantly repeated. When bubble departs from a site on the electrode surface, it is assumed that an electrode surface area of $a_{d} A_{d}$ comes into contact with fresh bulk electrolyte having the bulk concentration of indicator ions, $c_{i}$, where $A_{d}$ is the cross-section of a detached bubble and $a_{d}$ is a constant factor.

To calculate the mass transfer coefficient the following additional simplifications are still made:

- the radius, the cross-section and the volume of all detached bubbles are constant and, respectively, $R_{d}$, $A_{d}$ and $V_{d}$;

- the distribution of the bubble-depart sites across the electrode surface is uniform;

- the bubble cycle time $t_{d}$ is equal for all electrode sites:

- the detaching and rising bubbles induce no solution flow except the flow necessary for refreshment of solution at the electrode surface.

From the rate of volumetric gas bubble formation per unit surface area, $v_{g, b}$, and the volume $V_{d}$ of a detached bubble it follows that the number of detached bubbles per unit surface area and time

$$
N=v_{g, b} / V_{d} .
$$

Since the density of sites from which bubbles depart, $d=N t_{\mathrm{d}}$, the fraction of electrode surface coming into contact with fresh bulk electrolyte in period $t_{d}$ is given by

$$
s=N t_{d} a_{d} A_{d} .
$$

In the absence of migration and convection, the mass transfer coefficient for indicator ions can be obtaincd by so-called scmi-infinitc lincar diffusion at a plane electrode.

The mass transfer coefficient for indicators, $k_{i}$, can be derived from the well known relation for the rate of mass transfer. It can be shown that

$$
k_{i}=D_{i}^{1 / 2} / \pi^{1 / 2} t^{1 / 2}
$$

where $t$ is the time passed after detachment of a bubble. At $t=0$ the concentration of indicator ions does not depend on the distance from the electrode surface.

For the fractions of the electrode surface coming into contact with fresh bulk electrolyte after detachment of bubbles, the average mass transfer coefficient for indicator ions, $k_{i, a}^{\prime}$ in the period $t_{d}$ is

$$
k_{i, a}^{\prime}=\frac{1}{t_{d}} \int_{0}^{t_{d}} k_{i}^{\prime} \mathrm{d} t \text {. }
$$

After introduction of Equation (3) into Equation (4) and after integration of the resulting integral it is found that

$$
k_{i, a}^{\prime}=2 D_{i}^{1 / 2} / \pi^{1 / 2} t_{d}^{1 / 2}
$$

Since in a convectionless solution the mass transfer coefficient for the uncovered fraction $1-s$ of the electrode surface not coming into contact with fresh solution is zero, the total mass transfer coefficient $k_{i}^{0}$ for a gas-evolving electrode in a convectionless soluton

$$
k_{i}^{0}=k_{i, a}^{\prime} s \text {. }
$$

From Equations (1), (2) and (6) it follows that

$$
k_{i}^{0}=2 a_{d} A_{d i} v_{g, b} D_{i}^{1 / 2} t_{d}^{1 / 2} / \pi^{1 / 2} V_{d} .
$$

From relations (1), (2) and (7) it can be shown that

$$
k_{i}^{0}=2 a_{d} A_{d} D_{i}^{1 / 2} v_{g, b}^{1 / 2} d^{1 / 2} / \pi^{1 / 2} V_{d}^{1 / 2} .
$$

The mass transfer coefficient for indicator ions to a gas-evolving electrode in a convectionless solution is described by Equations (7) as well as by Equation (8).

The effect of forced convection on mass transter coefficient is discussed in the next section.

For a bubble-free electrode surface under forced convection the mass transfer coefficient is given by $k_{f}$. Consequently, for the fraction $1-s$ of the electrode surface not in contact with fresh bulk electrolyte the mass transfer coefficient is equal to $k_{f}$ :

For the fraction $s$ of electrode surface in contact with fresh bulk solution, the calculation of the average mass transfer coefficient is complicated. During the bubble cycle the mass transfer coefficient is greater than $k_{f}$ directly after bubble detachment and becomes equal to $k_{f}$ after a certain time $t_{\mathbf{l}}$.

The solution in the diffusion layer is regarded as a convectionless solution.

The mass transfer coefficient, directly after bubble detachment, is equal to $k_{i}^{\prime}$. Since $k_{f}^{\prime}$ at $t_{1}$ is equal to $k_{f}$, it can be shown that

$$
t_{1}=D_{i} / \pi k_{f}^{2} \text {. }
$$

The bubble cycle time $t_{d}$ is divided into two parts, viz $t_{1}$ and $t_{d}-t_{1}$.

For the fraction $s$ of the electrode surface and assuming the bubble cycle time is greater than $t_{1}$, the mass transfer coefficient during time $t_{d}-t_{1}$ is given by $k_{f}$ and the average one during time $t_{1}$ by

$$
k_{f, i, \alpha}^{\prime}=\frac{1}{t_{1}} \int_{0}^{t_{1}} k_{i}^{\prime} \mathrm{d} t .
$$

By substitution of $k_{i}^{\prime}$ by Equation (3) into Equation (10) and after integration it follows that

$$
k_{j, i, a}=2 D_{i}^{1 / 2} / \pi^{1 / 2} t_{1}^{1 / 2} .
$$

The mass transfer coefficient averaged over one bubble cycle

$$
k_{f, i, a^{*}}^{\prime}=\frac{k_{f, i, a}^{r} t_{1}+k_{f}\left(t_{d}-t_{1}\right)}{t_{d}}
$$

From Equations (9), (11) and (12) it is found that

$$
k_{f, i, a^{*}}^{\prime}=k_{f}+\frac{D_{i}}{\pi k_{f} t_{d}} \text {. }
$$

The total mass transfer coefficient for a gas-evolving electrode under forced convection is

$$
k_{i}=k_{f}(1-s)+k_{f, i, a^{*}}^{\prime} s \text {. }
$$

From Equations (13) and (14) it follows that

$$
k_{i}=k_{f}+\frac{D_{i} s}{\pi k_{s} t_{d}}
$$


and from Equations (1), (2) and (14) that

$$
k_{i}=k_{f}+\frac{D_{i} a_{d} A_{d} v_{g, b}}{\pi k_{f} V_{d}} .
$$

The first term of Equation (16) incorporates the mass transfer at forced convection and in the absence of gas bubble formation; the second term gives the contribution caused by detached bubbles.

In the next discussion, it is assumed that $t_{1}>t_{\mathrm{d}}$. Since, in this case $k_{f, i, a^{*}}^{\prime}=k_{f, i, a}^{\prime}$, the mass transfer coefficient $k_{i}$ is given by

$$
k_{i}=k_{f, i}(1-s)+k_{f, i, a}^{\prime} s .
$$

When the first term of Equation (17) is much smaller than the second one, then

$$
k_{i}=k_{S, i, a^{*}}
$$

From Equations (1), (2), (11) and (18) and substituting $t_{1}$ of Equation (11) by $t_{d}$ it follows that

$$
k_{i}=\frac{2 a_{d} A_{d} D_{i}^{1 / 2} v_{g, b}^{1 / 2} d^{1 / 2}}{\pi^{1 / 2} V_{d}^{1 / 2}} .
$$

Comparing Equations (19) and (8) shows that, in this case, the relations for $k_{i}$ and $k_{i}^{0}$ are equal.

\section{DISCUSSION}

\subsection{Behaviour of detached bubbles}

The size of a bubble at the moment of departure from the electrode surface is less than that of rising bubbles when coalescence of detached bubbles occurs. Coalescence of detached bubbles is affected by various factors, eg bubble density, solution flow velocity, length of bubble trajectory in the electrolytic cell and the nature of gas and solution. The literature on electrochemically formed gas bubbles has been recently reviewed by Vogt[14].

Results on the behaviour of oxygen as well as hydrogen bubbles formed during electrolysis at forced convection have already been published $[10,15,16]$.

The average radii for oxygen as well as hydrogen detached bubbles are proportional to, respectively, $i_{\mathrm{O}}^{0.44}$ and $i_{\mathrm{H}}^{0.27}$ (Sections 3.1.1. and 31.2). Both dependences are clearly greater than those found by Bongenaar et al.[15]. They determined the radius of bubbles at the outlet of an electrolysis cell with a 50cm-high working electrode in $30 \mathrm{wt} \% \mathrm{KOH}$ at a temperature of $353 \mathrm{~K}$ and solution flow velocity of $0.5 \mathrm{~m} \mathrm{~s}^{-1}$.

The experimental conditions in this investigation, however, deviate strongly from those used in $[15,16]$, so that only a qualitative agreement might be expected.

Since bubbles present in the solution just above the top of the working electrode were pictured, and also the low height of the working electrode, viz $5.45 \mathrm{~mm}$, it is likely that coalescence of bubbles rising in the solution will not have a significant effect on experimental bubble size.

The oxygen bubblcs, formed by coalescence of bubbles which had adhered to the electrode surface, jumped perpendicularly from the electrode surface[4].

The density of rising oxygen bubbles in the solution near the electrode surface is relatively low, since no layer of free oxygen bubbles glides over the layer of attached oxygen bubbles[16]. At the hydrogenevolving electrode bubbles glide over the layer of attached hydrogen bubbles. It is well known, that in alkaline solution, hydrogen bubbles do not coalesce as easily as oxygen bubbles do. Consequently, the bubble size determined in this investigation is almost equal to that for the bubbles departing from the electrode surface. Obviously, coalescence of attached bubbles can affect the experimental results strongly.

\subsection{Efficiency of gas evolution}

The efficiency of gas evolution is much higher for the hydrogen-evolving electrode than for the oxygenevolving electrode (Figs 6 and 7). The calculated efficiency of gas evolution given in [9] is very much less than the experimental results given in Fig. 7. Additional experiments are necessary to obtain more accurate results.

It is likely that the efficiency of gas evolution determined from pictures just above the top of the working electrode, is less than that for the working clectrode because of gas absorption by bubbles rising from the supersaturated solution near the gas-evolving electrode. Assuming a negligible difference in both efficiencies, the supersaturation of gas at the gasevolving electrode can be calculated when the mass transfer coefficient for the dissolved gas is well known. Assuming that $k$ for the gas-evolving cylindrical electrode used in measuring the efficiency of gas evolution is equal to the gas-evolving flat-plate electrode then, using $D_{H}=3.0 \times 10^{-9} \mathrm{~m}^{2} \mathrm{~s}^{-1}[17], D_{\mathrm{O}}=1.59$ $\times 10^{-9} \mathrm{~m}^{2} \mathrm{~s}^{-1}[18], D_{f i}=7.9 \times 10^{-10} \mathrm{~m}^{2} \mathrm{~s}^{-1}, D_{f o}$ $=7.0 \times 10^{-10} \mathrm{~m}^{2} \mathrm{~s}^{-1}[11]$ and the relations $k_{\mathrm{H}}$ $=\left(D_{\mathrm{H}} / D_{f i}\right)^{1 / 2} k_{f i}$ and $k_{\mathrm{O}}=\left(D_{\mathrm{o}} / D_{f o}\right)^{1 / 2} k_{f o}$, it can be calculated that the hydrogen supersaturation of the solution at a hydrogen-evolving electrode in $1 \mathrm{M} \mathrm{KOH}$ and at $1 \mathrm{kA} \mathrm{m}^{-2}$ and $v_{s}=0.12 \mathrm{~m} \mathrm{~s}^{-1}$ is equal to $25 \mathrm{mM}$ and the oxygen supersaturation of the solution at an oxygen-evolving electrode in $1 \mathrm{M} \mathrm{KOH}$ and at $1 \mathrm{kA} \mathrm{m}^{-2}$ and $v_{s}=0.12 \mathrm{~m} \mathrm{~s}^{-1}$ is $23 \mathrm{mM}$. This result agrees very well with that obtained with a rotating ring-cone electrode[19].

\subsection{Mass transfer at gas-evolving electrode}

Gas bubble evolution at an electrode causes solution flow near the electrode surface. For a hydrogenevolving electrode in alkaline solution, the hydrodynamic model was proposed to describe the mass transfer of indicator ions 57 . In this model, the effect of the solution flow induced by bubbles is taken into account exclusively. It is likely that this effect is reduced at increasing velocity of forced solution flow.

Gas bubbles formed at an electrode block the current passage for a part of the electrode surface during their attachment and impede the mass transfer of indicator ions to the electrode surface. After detachment, the space which had been occupied by the detached bubbles is filled up with solution. In the coulescence model used to describe the mass transfer of indicator ions to an oxygen-evolving electrode in alkaline solution [4], it is assumed that this solution has the composition of bulk solution. The solution flow needed to fill up the space occupied by detached bubbles is considered as a solution flow, the velocity of 
which has no direct effect on the rate of mass transfer.

The bubble density $d$ has to be used to calculate $t_{d}$. Unfortunately, this factor is unknown. For the sake of reliability it is assumed that $t_{1}<t_{d}$ if $k<3 k_{e}$, in the case that $k_{e}=k$ in the absence of bubble formation and has been obtained by extrapolation of the $k / i$ curve. Consequently, relation (16) is only used at relatively low values of $k$, viz $k<3 k_{e}$.

It is assumed in the following sections that the experimental results obtained for the wire electrode can be used to elucidate the mass transfer measurements for the rectangular plate electrode.

5.3.1. Oxygen-evolving electrode. From Figs 4 and 6 , the factor $D_{f_{0}} A_{d} v_{g, b} / \pi V_{d}$ at $v_{s}=0.12 \mathrm{~ms}^{-1}$ and at various $i_{\mathrm{o}}$ can be determined when it is taken into consideration that $R_{S, d}=3 V_{d} / 4 A_{d}, v_{g, b}=\eta_{g} v_{g}^{o}$ and $v_{g}^{o}$ $=i_{\mathrm{O}} V_{M} / 4 F$.

Since $V_{M}=24.5 \times 10^{-3} \mathrm{~m}^{3} \mathrm{~mol}^{-1}$ it follows that at $298 \mathrm{~K} v_{g}^{\mathrm{o}}=0.634 \times 10^{-4} i_{\mathrm{O}} \mathrm{m} \mathrm{s}^{-1}$ where $i_{\mathrm{O}}$ is given in $\mathbf{k A ~ m}^{-2^{g}}$.

It has been found that, for the oxygen-evolving electrode at $v_{s}=0.06$ and $0.12 \mathrm{~ms}^{-1}, k_{c_{\text {, fo }}}$ is higher than $k_{f, f_{0}}$. This means that the effect of the hydrodynamic convection of solution which occurs at very low current densities, viz $<0.05 \mathrm{kA} \mathrm{m}^{-2}$, has to be taken into account. To verify the proposed model, $k_{e, f o}$ has to be used.

For an oxygen-evolving electrode the factor $\left(k_{f_{0}}\right.$ $\left.-k_{e, f_{o}}\right) k_{e, f_{o}}$ is plotted os $D_{f a} A_{d} v_{g, b} / \pi V_{d}$ in Fig. 10 . The experimental results are scattered around a straight line with a slope $a_{d, O}$ of 1.7 . This means that the refreshment mechanism is very effective in enhancing the mass transfer of indicator ions to the surface of an oxygen-evolving electrode.

For the oxygen-evolving electrode, the hydrodynamic mechanism is of still less importance in this case, because of the behaviour of detaching oxygen bubbles. These bubbles jump perpendicularly from the electrode surface and cause only a weak vertical hydro- dynamic flow of solution near the electrode surface. The detached rising oxygen bubbles do not form a curtain near the electrode surface as the detached rising hydrogen bubbles do.

Assuming $t_{1}>t_{\mathrm{d}}$ at $i_{\mathrm{O}}>1 \mathrm{kA} \mathrm{m}^{-2}$, the mass transfer coefficient is then given by Equation (19). From Equation (19) it can be deduced that $d=V_{d} k_{f o}^{2} / 4 a_{d}^{2} A_{d}^{2} D_{f o} v_{d, b}$. The bubble density $d$ is calculated at various $i_{O}$ and at $v_{s}=0.12 \mathrm{~m} \mathrm{~s}^{-1}$.

Using the mass transfer coefficient $k_{\text {fa }}$, viz 14 $\times 10^{-5}, 9.5 \times 10^{-5}$ and $3.6 \times 10^{-5} \mathrm{~m} \mathrm{~s}^{-1}$ for, respectively $i_{\mathrm{O}}=10,5$ and $1 \mathrm{kA} \mathrm{m}^{-2}, \quad D_{f o}=7.0$ $\times 10^{-10} \mathrm{~m}^{2} \mathrm{~s}^{-1}[11], a_{d . \mathrm{Q}}=1.7$ (Section 5.3.1) $v_{0 . \mathrm{b}}$ $=0.634 \times 10^{-4} f_{g} i_{0} \mathrm{~m} \mathrm{~s}^{-\mathrm{P}}, \quad A_{d}=2.4 \times 10^{-9} i_{0}^{0.85} \mathrm{~m}^{2}$ (Section 3.14) and $V_{d}=1.2 \times 10^{-13} i_{0}^{1.21} \mathrm{~m}^{3}$ where $i_{o}$ is given in $\mathrm{kA} \mathrm{m}^{-2}$ it was calculated that $d_{\mathrm{o}}=1.18 \times 10^{8}$, $1.58 \times 10^{8}$ and $2.60 \times 10^{8} \mathrm{~m}^{-2}$ for, respectively $i_{0}$ $=10,5$ and $1 \mathrm{kA} \mathrm{m}^{-2}$. In this case, $d_{O}$ is proportional to $i_{0}^{-0.34}$.

When $d$ is taken as $A_{d}^{-1}$, it can be shown that in that case $d_{\mathrm{O}}=0.59 \times 10^{8}, 1.06 \times 10^{8}$ and $4.16 \times 10^{8} \mathrm{~m}^{-2}$ for, respectively $i_{O}=10,5$ and that $1 \mathrm{kA} \mathrm{m}^{-2}$ and $d_{0}$ is proportional to $i_{0}^{0.9}$. Comparing both series of $d_{0}$, it follows that the order of their magnitude is the same but that their dependence on $i_{o}$ differs strongly.

The density of bubbles present on the electrode surface is proportional to about $i_{0}^{0.9}[10]$. In particular, it was found that an increasing number of attached bubbles are small ones.

A great part of these small bubbles coalesce without forming detached bubbles. Consequently, it is likely that these small bubbles can be left out of consideration in describing the mass transfer of indicator ions to a gas-evolving electrode.

From the preceding discussion it can be concluded that the new model can describe the mass transfer of indicator ions to an oxygen-evolving electrode at forced as well as at natural convection. In the latter case, some effect of hydrodynamic flow of solution will also occur at low current densities.

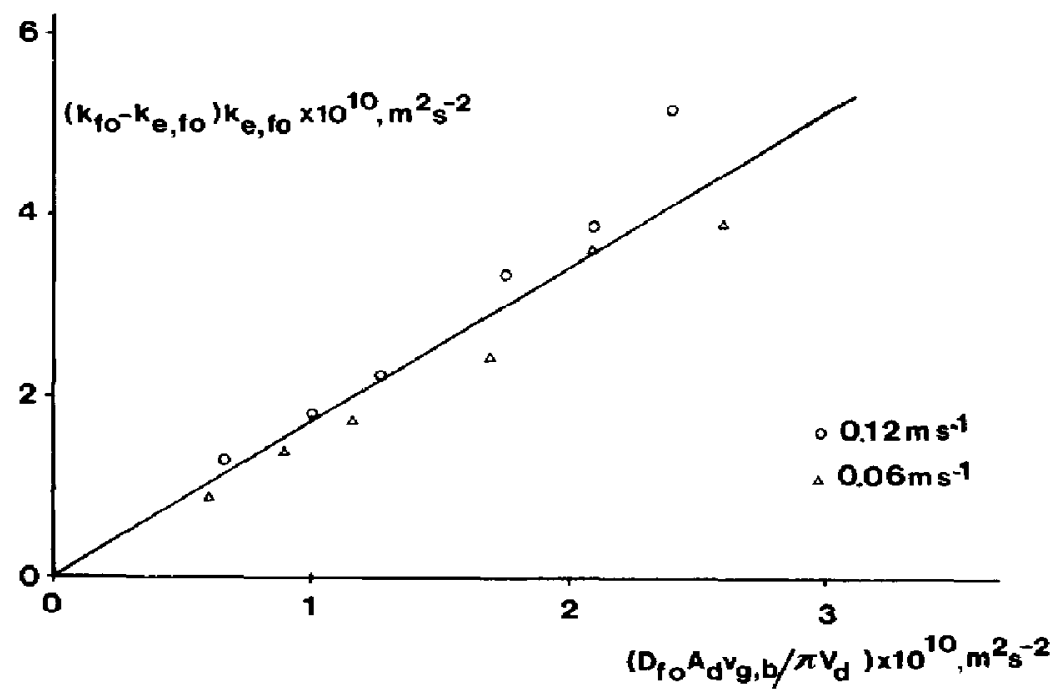

Fig. 10. The factor $\left(k_{f_{0}}-k_{e, f_{0}}\right) k_{e, f_{o}}$ is plotted os $D_{f_{0}} A_{d} v_{g, b} / \pi V_{d}$ for an oxygen-evolving nickel electrode in $1 \mathrm{M} \mathrm{KOH}$ and at $298 \mathrm{~K}$ and two different bulk-solution-flow velocities. 


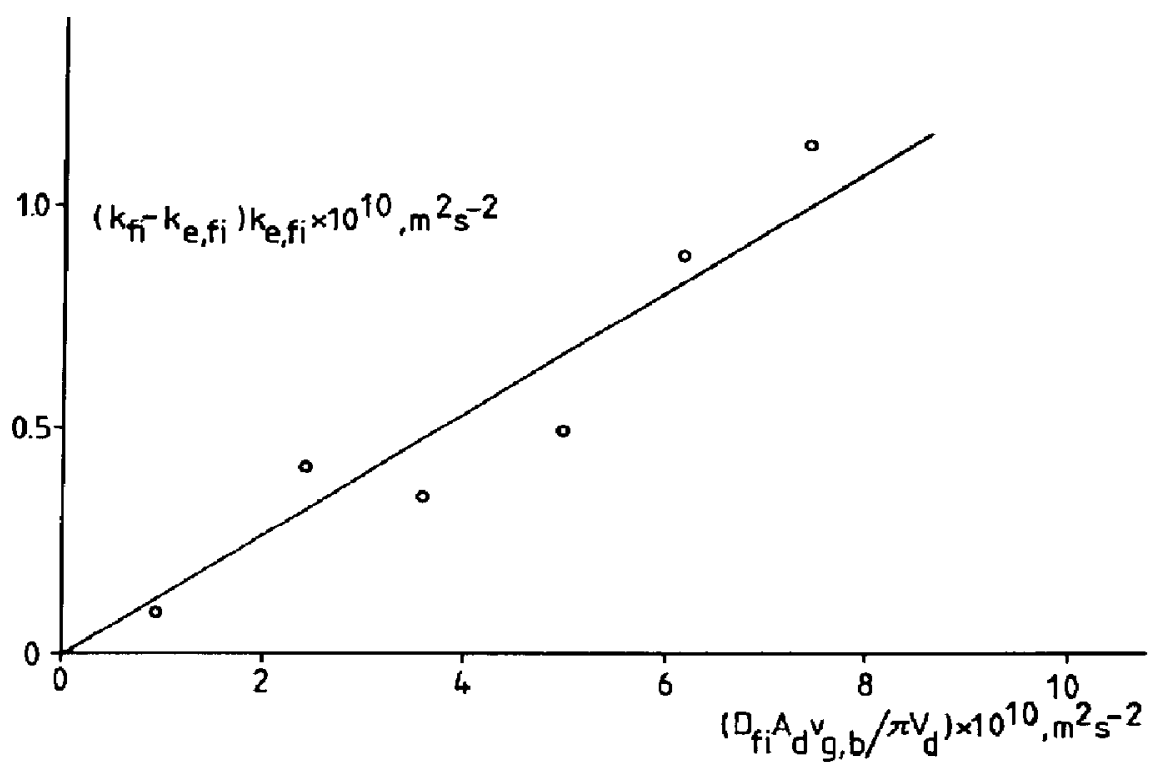

Fig. 11. The factor $\left(k_{f i}-k_{e, f t}\right) k_{e, f^{t}}$ is plotted $v s D_{f t} A_{d} c_{\mathrm{g}, b} / \pi V_{d}$ for a hydrogen-evolving nickel electrode in $1 \mathrm{M} \mathrm{KOH}$ and at $298 \mathrm{~K}$ and a bulk-solution-flow velocity of $0.12 \mathrm{~ms}^{-1}$.

5.3.2. Hydrogen-evolving electrode. From the $k_{f i} / i_{\mathrm{H}}$ curves and $k_{f, f i}$ at various $v_{s}$, it follows that in the range of very low $i_{\mathrm{H}}, v i z<0.02 \mathrm{kA} \mathrm{m}^{-2}, k_{f i}$ increases from $k_{f, f i}$ at current densities $i_{\mathrm{H}}$ where no bubble formation takes place, to a much higher value than $k_{f, f i}$ at $i_{\mathrm{H}}>0.02 \mathrm{kA} \mathrm{m}^{-2}$. The increase of $k_{f i}$ with increasing $i_{H}$ is much lower and is proportional to $i_{H}$ (Fig. 9). This increment is caused either by a stronger flow of solution near the electrode surface or an increasing effect of solution refreshment at the electrode surface or by both.

In the following discussion, it is assumed that it is only this refreshment mechanism that determines the increment of $k_{f i}$.

In the range of current densities $i_{\mathrm{H}}$ where $k_{f i}$ $<3 k_{e, f i}$, it- is assumed, in the casc of the oxygenevolving electrode, that the rate of mass transfer coefficient for the hydrogen-evolving electrode is given by Equation (16).

For hydrogen-evolving electrodes it has been found that $k_{e, f i}$ is clearly higher than $k_{f, f i}$ in the investigated range of solution flow velocities. This result can be explained by the formation of a curtain of rising bubbles near the electrode surface and by slipping bubbles attached to the electrode surface.

In the range of very low current densities both phenomena cause a hydrodynamic flow of the solution enhancing the mass transfer near the electrode surface.

To elucidate the contribution of the refreshment mechanism to mass transfer, it is preferred to use $k_{*}$ instead of $k_{f}$.

In Fig. 11 the difference $k_{f i} k_{e, f_{i}}-k_{e, f_{i}}^{2}$ (Fig. 9) is plotted $v s D_{r i} A_{d} v_{a, b} / \pi V_{d}$ (Figs $S$ and 7 ) for a hydrogenevolving electrode at $v_{s}=0.12 \mathrm{~m} \mathrm{~s}^{-1}$, where $\boldsymbol{R}_{S \text {,d }}$ $=3 V_{d} / 4 A_{d}, v_{g, b}=\eta_{g} v_{g}^{0}$ and $v_{g}^{0}$ at $298 \mathrm{~K}$ is $1.268 \times 10^{-4}$ $i_{\mathrm{H}} \mathrm{m} \mathrm{s}^{-1}$ where $i_{\mathrm{H}}$ is given in $\mathrm{kA} \mathrm{m}^{-2}$. The slope of the straight line drawn in Fig. 11 is equal to $a_{d . H}=0.14$.
This value of $a_{d, H}$ is low and indicates low effectiveness of the refreshment mechanism for the hydrogenevolving electrode. If the hydrodynamic mechanism also contributes to the increment of the mass transfer coefficient at $v_{s}=0.12 \mathrm{~m} \mathrm{~s}^{-1}$, the factor $a_{d, H}$ has then to be smaller than 0.14. In this case, the effectiveness of the refreshment mechanism becomes still lower.

\section{REFERENCES}

1. H. Vogt, Comprehensive Treatise of Electrochemistry (Edited by E. Yeager, J. O'M. Bockris, B. E. Conway and S. Sarangapani), Vol. 6, p. 445 (1983).

2. N. Ibl, E. Adam, J. Venczel and E. Schalch, Chem. Ing. Tech. 43, 202 (1971).

3. K. Stephan and H. Vogt, Electrochim. Acta 24, 11 (1979).

4. L. J. J. Janssen und S. J. D. van Straken, Electrochim. Acta 26, 1011 (1981).

5. L. J. J. Janssen and E. Barendrecht, Electrochim. Acta 24, 693 (1979).

6. I. Rousar and V. Cezner, Electrochim. Acta 20, 289 (1975).

7. T. R. Beck, I. electrochem. Soc. 116, 1038 (1969).

8. H. Vogt, Electrachim. Acta 23, 205 (1978).

9. H. Vogt, Extended Abstracts 34th meeting ISE, Erlangen, 0413 (1983).

10. C. W. M. P. Sillen, Thesis, Eindhoven University of Technology (1983).

11. L. J. J. Janssen, Electrochim. Acta 23, 81 (1978).

12. J. M. Kolthoff and E. B. Sandell, Textbook of Quantitative Inorganic Analysis. Macmillan, New York (1952).

13. L. J. J. Janssen and J. G. Hoogland, Electrochim. Acta 18, 543 (1973).

14. H. Vogt, Fortschritte der Verfahrenstechnik 20, 369 (1982).

15. B. E. Bongenaar-Schlenter, L. J. M. Konings, C. J. Smeyers, J. H. G. Verbunt, E. Barendrecht, L. J. J. Janssen, W. M. Sluijter and S. J. D. van Stralen, 
Hydrogen as an energy carrier, Proc. 3rd Int. Seminar, Lyon 25-27 May 1983, p. 206. D. Reidel, Dordrecht (1983).

16. L. J. J. Janssen, C. W. M. P. Sillen, E. Barendrecht and S. J. D. van Stralen, Electrochem. Acta 29, 633 (1984).
17. A. M. Yatkovski and N. A. Fedotov, R. J. Phys. Chem. 43, 575 (1969).

18. F. T. B. J. van den Brink, Thesis Eindhoven (1981)

19. L. J. J. Janssen and E. Barendrecht, Electrochim. Acta 29, 1207 (1984). 